\title{
Powering-Up Primary Care Teams: Advanced Team Care With In-Room Support
}

\author{
Cbristine A. Sinsky \\ Thomas Bodenbeimer, MD, MPH \\ ${ }^{1}$ American Medical Association, Chicago, \\ Illinois \\ ${ }^{2}$ University of California, San Francisco, \\ San Francisco, California
}

\begin{abstract}
Primary care teams are underpowered. Teams do not maximally redistribute team functions when clinicians are diverted from activities where they add the most value. This commentary describes "advanced team care with in-room support" as a way to "power-up" primary care teams. In this core team model, each clinician is paired with 2 or 3 highly trained medical assistants or nurses-care team coordinators (CTCs).Early evidence suggests that this model is more satisfying to clinicians, staff, and patients and is financially sustainable. Yet its spread has been hobbled by several misguided beliefs, such as that the physician can and should do most tasks, that technology replaces people, that health care is a transactional endeavor more than a therapeutic relationship, that regulation is the main lever by which to advance quality, and that the principal way to increase net revenue is to reduce overhead. A shift in mindset is needed to energize primary care.
\end{abstract}

Ann Fam Med 2019;17:367-371. https://doi.org/10.1370/afm.2422.

$\mathrm{P}$ rimary care teams are underpowered. They are underpowered because they do not maximally redistribute team functions. Clinicians (physicians and advanced practice providers) are often diverted from activities where they add most value (medical decision making and relationship building) to tasks that do not require a medical education (documentation, order entry, billing invoice creation, etc.) A new team model is bubbling up across the country with the potential to reinvigorate primary care. This commentary describes "advanced team care with in-room support" and proposes a "mindshift" to further the spread of this model.

Most primary care is delivered in an outmoded model, which has been described as a frantic physician running from visit to visit with a skeletal support staff who is kept out of the visit and therefore unable to optimally contribute. ${ }^{1}$ The advanced team model with in-room support changes this balance in favor of optimally utilizing clinician resources.

Too often, primary care is unsatisfying to clinicians and patients alike. It would take a primary care physician without a team 17 hours per day to provide recommended care to a panel of 2,000 patients. ${ }^{2}$ Less than onethird of the physician's day is spent in face-to-face time with patients and one-half is consumed in electronic health record (EHR) documentation and desk work. ${ }^{3}$ To top it off, primary care physicians routinely spend 1 to 2 more hours each evening on inbox and documentation work. ${ }^{3,4}$

The deficiencies are not lost on patients. In a recent poll, almost onehalf of US adults were not satisfied with their most recent physician visit. ${ }^{5}$ Forty to eighty percent of patients leave the office visit without understanding what the physician said. ${ }^{6}$ The recent decline in visits to primary care could be an ominous warning for the future. ${ }^{7}$

Over the past 15 years an intentional, coherent new model of primary care has surfaced in a handful of practices across the country. ${ }^{8-13}$ Early evidence suggests that this model—advanced team care with in-room support—makes primary care more satisfying to clinicians, staff, and patients, while enhancing quality. ${ }^{12,14}$ Yet its spread has been hobbled by several
Thomas Bodenheimer, MD, MPH Center for Excellence in Primary Care University of California, San Francisco 995 Potrero Ave, 3rd floor

San Francisco, CA 94110

Tombodie3@gmail.com 
misguided assumptions, or mindsets, starting with the view that the physician can and should do most tasks. Other unhelpful mindsets include the assumptions that technology replaces people, that health care is a transactional endeavor more than a therapeutic relationship that regulation is the main lever by which to advance quality, and that the principal way to increase net revenue is to reduce overhead.

\section{ADVANCED TEAM CARE WITH IN-ROOM SUPPORT}

The core team (or teamlet) of an advanced care team with in-room support is comprised of a clinician and 2 or 3 medical assistants or nurses, hereafter referred to as care team coordinators (CTCs). The higher the skill level of the CTC, the more responsibilities are shared. Ideally, an extended care team of additional colocated health professionals, such as a pharmacist, social worker, and behaviorist, support several core teams.

This model extends the clinician visit into a team visit; a clinician and CTC conduct in-person visits together. The CTC begins the visit, taking the initial history, often using symptom-specific sets of questions; closing chronic and preventive care gaps (immunizations, cancer screenings, and routine diabetes services); performing medication reconciliation; and setting the visit agenda based on the patient's and team's concerns. After 10-15 minutes, the CTC does a brief warm handoff to the clinician who joins the visit.

The clinician sits face-to-face with the patient (without the computer dividing her attention); deepens the relationship; expands the history; does a focused physical exam; and discusses diagnosis, prognosis, and a collaborative care plan. The CTC accesses additional information in the EHR as needs arise; performs realtime in-room documentation; and enters orders agreed upon by patient and clinician. The clinician then leaves and the CTC reviews the care plan; arranges labs, imaging, referrals, and follow-up visits; and may provide health coaching on medication adherence and healthy behaviors. While the CTC is finishing the visit and starting the next visit, the clinician is in another room with the second CTC's patient. Between visits, the clinician takes a few minutes to edit and close the previous patient's note-approving orders if needed and finalizing the assessment and plan. Between visits, CTCs manage the majority of inbox and telephone messages, and provide care coordination and navigation assistance for patients, which they can do with greater proficiency and more personalized care because they participate in the visits and know the patients and the plan. CTCs are far more than scribes; they are true clinical partners.
CTCs are trained and supervised by a lead CTC and the clinician with whom they work, with periodic performance audits. If the CTCs are nurses, their precise roles need to conform to the state nurse practice act. If the CTCs are medical assistants, they generally fall under medical practice regulations.

\section{EVIDENCE TO SUPPORT THIS MODEL}

Early evidence supports the adoption of advanced team care with in-room support, and more robust evaluation is ongoing. We present evidence from 4 early demonstration sites. The model was pioneered by family physician Peter Anderson in Virginia ${ }^{9}$ and the author's (C.S.) practice in Iowa, ${ }^{11}$ both partnering with nurses. Anderson reported improvement in clinical quality; patient access; patient, physician, and staff satisfaction; and practice revenues. Kevin Hopkins, a family physician at a Cleveland Clinic site, initiated the advanced team model in 2011 with medical assistants. Productivity increased by $20 \%$, net revenue per encounter grew $10.5 \%$, patient satisfaction increased, and blood pressure and diabetes control improved. In 2014, Dr Hopkins saw an average of 29 patients per day, left the office at 5:15 pm, and did no EHR work at home. ${ }^{15}$

Bellin Health in northeastern Wisconsin piloted the model in 2014 using medical assistants and licensed practical nurses; by 2018 it had spread to over 100 primary care clinicians at Bellin. Teams in this model achieved better performance on 13 of 15 quality metrics than those not yet using the advanced team care model. ${ }^{15}$ Patient and staff satisfaction increased, and clinician satisfaction went from $34 \%$ without the team model to $88 \%$ with the model. On average, the health system is receiving an additional $\$ 724$ in payments per patient per year. ${ }^{16}$

In its family medicine residency clinic and other primary care sites, University of Colorado Health System employs this model using medical assistants trained in its 3-week MA Academy (curriculum available from author [T.B.]) and subject to periodic reliability audits to evaluate and sustain their competence. To mitigate the problem of turnover, the health system is making sure that medical assistant pay/benefits are at least on par with competing health systems, and offers a career ladder, including pay increases. Third-year residents participate fully in the model. University of Colorado data show an increase in capacity (156\% increase in new patients), greatly improved access, and better hypertension control and cancer-screening rates. Patient experience improved for staff and clinician communication, as well as patients' willingness to recommend the practice to others. Physician burnout dropped from $56 \%$ to $28 \%$ in 1 year and after-hours 
EHR work declined. The additional patient visits pay for the augmented staff. ${ }^{14}$

It is early in the implementation of advanced team care with in-room support. Early adopter teams may be more successful than later entrants because physicians are highly motivated and attract the most competent and enthusiastic staff. Yet common findings across these sites include increased capacity for patient care and improved satisfaction for patients, staff, and clinicians. The model appears to be financially sustainable under both fee-for-service and value-based payment. Under fee-for-service, practices pay for added personnel with 2 to 3 more patient visits per day per clinician, better documentation allowing more accurate coding, and greater ancillary revenues from more preventive screenings. Under value-based payment, the practice can pay for the additional staff with larger panel sizes/patient volume, improved metrics, and physicians having time to keep patients out of the hospital and reduce downstream costs. Because CTCs participate in the patient visit, their work is more interesting, they can better address patient needs, they feel pride in their work, and practice-debilitating staff turnover may be reduced.

Advanced team care with in-room support is by no means the only available improvement in primary care..$^{17,18}$ Other workflow enhancements-previsit planning, previsit lab and synchronized prescription renewal—save time and improve care. ${ }^{18}$ The direct primary care model markedly reduces panel size so that physicians can comfortably care for their patients without a team, however, the panel size reduction exacerbates the primary care shortage. ${ }^{19}$ The retail clinic model creates store-based, usually nurse practitioner-run, lowcost, same-day access clinics for minor acute problems, but has less value for patients with chronic conditions. ${ }^{20}$ The interprofessional team model, an extended care team that assists the core team for certain patients, focuses on professionals_pharmacists, nurses, behaviorists, social workers-who can together care for specific clinical conditions. ${ }^{21}$ The highrisk clinic ("intensive ambulatory care unit") model would separate high-needs, high-cost patients from routine primary care, offering intensive team care to panels of 400 patients. ${ }^{22}$
These models do not transform the core team. The advanced team care with in-room support model optimizes the proactive planned care visits necessary in a chronically ill population and increases capacity to manage same-day acute care visits. Other models_-retail clinics for acute problems, interprofessional teams to extend the work of the core team, high-risk clinics to bring high-needs patients into more intensive care-are extended care team models that can wrap around the core team model but do not substitute for the need to power-up the core team.

\section{IMPEDIMENTS TO ADOPTION}

Several commonly held mindsets limit widespread adoption of advanced team care with in-room support (Table 1).

\section{The Doctor Does It All}

In this mindset the physician is a lone actor, the sole individual whose interaction with the patient contributes to health. ${ }^{23}$ "If I don't do it, it won't get done." Only a physician and computer belong in the exam room with the patient. Every element of care passes through the physician-computer dyad: even diabetic shoes cannot be authorized without a physician's signature. Central to enabling this mindset is the self-sacrificing nature of the physician as hero; ${ }_{i}$ willingness to give up hours of personal life in service to patients, even when much of that service is clerical work that could be delegated or

\section{Table 1. Old vs New Mindsets}

\begin{tabular}{|c|c|}
\hline Old Mindsets & New Mindsets \\
\hline The doctor does it all. & $\begin{array}{l}\text { Share the care with the team: there is too much work to } \\
\text { be done by } 1 \text { person, and it is too important to be left } \\
\text { to chance. }\end{array}$ \\
\hline $\begin{array}{l}\text { The nonclinician team members } \\
\text { have minimal skills and make limited } \\
\text { contributions; so few are needed. }\end{array}$ & $\begin{array}{l}\text { A well-trained and mentored team of at least } 2 \text { clinical } \\
\text { assistants (MAs or nurses) per clinician is needed to fully } \\
\text { leverage the skills of all. Care is better and more satisfy- } \\
\text { ing if work is strategically delegated according to ability. }\end{array}$ \\
\hline $\begin{array}{l}\text { Technology replaces people, there- } \\
\text { fore fewer people are needed. }\end{array}$ & $\begin{array}{l}\text { People provide health care; technology plays a support- } \\
\text { ing role. }\end{array}$ \\
\hline $\begin{array}{l}\text { Health care is a transactional } \\
\text { endeavor, the sum of many discrete } \\
\text { tasks: in this model anybody will do. }\end{array}$ & $\begin{array}{l}\text { Health care is a relational endeavor, founded on trust- } \\
\text { ing and healing relationships. Continuity with the same } \\
\text { people matters. }\end{array}$ \\
\hline $\begin{array}{l}\text { Regulatory over-reach: what you } \\
\text { want to do is not allowed. }\end{array}$ & $\begin{array}{l}\text { If what you want to do is safe and helps patients, do it. If } \\
\text { each team member is trained, mentored, and audited for } \\
\text { a certain task within the bounds of governmental regula- } \\
\text { tion, health systems should allow it. }\end{array}$ \\
\hline $\begin{array}{l}\text { Overhead cost accounting: margins } \\
\text { are tight, so we need to trim staff. } \\
\text { Clinicians will have to pick up the } \\
\text { slack and do work that the support } \\
\text { staff might have done. } \\
\text { If physicians leave the organization, } \\
\text { we will hire more physicians and/or } \\
\text { less costly clinicians. }\end{array}$ & $\begin{array}{l}\text { Opportunity cost accounting: by way of a simple hypo- } \\
\text { thetical example, with a staffing ratio of } 1: 1 \text { (CTC: MD) the } \\
\text { primary care team may have the capacity to see patients } \\
\text { that generate } 6 \text { RVUs per hour. With a staffing ratio of } 3: 1 \\
\text { the team will provide more patient visits that are more } \\
\text { comprehensive and may generate } 9 \text { RVUs per hour. The } \\
\text { difference is the opportunity cost: the organization lost } \\
\text { the opportunity to generate } 3 \text { more RVUs per hour. }\end{array}$ \\
\hline
\end{tabular}


eliminated. One observer found that "The physicians we observed experienced a workday as a series of nonstop, one-on-one interactions with a stream of patients, with little or no interaction with others on the team."'

\section{The Team Has Limited Expertise}

The flip side of the doctor doing almost everything is the team doing relatively little. In many practices only a small proportion of the work is shared with the team, meaning that few additional personnel are required. If a practice needs more capacity, the mindset is to hire more clinicians rather than more staff. This belief reinforces the lone doctor mindset: when there are few support staff with little training, of course the doctor does everything.

\section{Technology Replaces People}

In 2005, RAND Corporation researchers projected that health IT adoption could save more than $\$ 81$ billion annually. ${ }^{24}$ Years later there were no savings; in fact, new technology is a primary driver of expenditure growth for many common diagnoses. ${ }^{25}$ Technology can measure but not improve quality. ${ }^{26}$ In many industries, technology reduces the number of human beings required to do the work. But in health care, the opposite has occurred. The dominant technology-the electronic health record-has added rather than subtracted work. What took seconds per task before may now require minutes, and work previously done by others has now been shifted to physicians. In spite of these facts, technology_especially the EHR_dominates the clinical landscape.

\section{Transactional vs Relational Care}

Health care has shifted to a transactional, task-oriented mindset, delivered by interchangeable clinicians who may not know the patient. ${ }^{27,28}$ Because all care passes through the EHR, the expectation is that any clinician can step in and pick up the thread of care. Any body will do. In this mindset, interpersonal continuity of care ${ }^{29}$ fades in importance and knowledge is felt to be housed in the EHR rather than in the relationships among clinicians, patients and staff. ${ }^{30}$

\section{Regulatory Overreach}

Laws, regulations, and policies within the health system can actually make it difficult to share the care with the entire team. Some health systems forbid medical assistants from administering immunizations even when state regulations contain no such restriction against such administration. Compliance offices may not allow registered nurses (RNs) to carry out clinical care under standing orders even when state nursing boards may allow it. Federal and Joint Commission prohibitions against verbally communicating orders in hospital-affiliated ambulatory settings force physicians to spend their time entering orders for influenza vaccines, mammograms, and ear washes, etc. Even before the recent regulatory escalation, doctors in the United States were described as the most "second-guessed and paperwork-laden physicians in western industrialized democracies." ${ }^{\prime \prime} 1$

\section{Overhead vs Opportunity Cost Accounting}

An organization that focuses its fiscal efforts on reducing overhead will minimize the number and level of training of its staff, directing work previously done by support staff to the highest trained professionals. While this may appear to save money in the short run, it risks substantial opportunity costs. Opportunity costs include lost revenue opportunities when physicians are doing work that others could do and not doing work for which they are uniquely trained. Clinicians managing $30 \%$ fewer patients because they spend hours on administrative tasks is a poor business model. In addition, reducing staff adds to physician burnout, ${ }^{32}$ which increases physician turnover. With lost productivity during the vacancy, replacing a physician can cost a million dollars or more. ${ }^{33}$

\section{CHALLENGING THE MINDSETS}

A unifying theme linking the existing mindsets is that the result is underpowered primary care teams. Most current teams do not maximally redistribute team functions, which would allow clinicians to shed that portion of clinical and administrative work that a well-trained, well-staffed team could easily perform. The beliefs that doctors do almost everything and other team members do little only hinders such redistribution. The centrality of EHR technology and the plethora of regulations preventing the empowerment of other team members redistribute team functions in the opposite way-toward the clinician. It is financially imprudent not to maximize the time the highest trained professionals spend on work for which they are uniquely qualified. In short, teams are underpowered and team members-including clinicians-are under-empowered.

Advanced team care with in-room support challenges these mindsets by creating teams in which a sufficient number of well-trained and mentored support personnel can assist with the clinical care of patients and assume much of the administrative burden. By distancing the EHR from the patient-clinician interaction, technology assumes its rightful supportive role. Advanced team care with in-room support is about matching the work to the worker. 


\section{CONCLUSION}

The primary care delivery model of the future cannot rest on the staffing model of the past. The old mindsets that hinder primary care prevent teams from truly sharing the care. An advanced team care model with in-room support, emerging in a few primary care practices, has the potential to improve care for patients and satisfaction for clinicians and staff.

To read or post commentaries in response to this article, see it online at http://www.AnnFamMed.org/content/17/4/367.

Key words: primary care; patient care team

Submitted November 28, 2018; submitted, revised March 15, 2019; accepted April 9, 2019

\section{References}

1. Chesluk BJ, Holmboe ES. How teams work-or don't-in primary care: a field study on internal medicine practices. Health Aff (Millwood). 2010;29(5):874-879.

2. Yarnall KS, Østbye T, Krause KM, Pollak KI, Gradison M, Michener JL. Family physicians as team leaders: "time" to share the care. Prev Chronic Dis. 2009;6(2):A59.

3. Sinsky C, Colligan L, Li L, et al. Allocation of physician time in ambulatory practice: a time and motion study in 4 specialties. Ann Intern Med. 2016;165(11):753-760.

4. Arndt BG, Beasley JW, Watkinson MD, et al. Tethered to the EHR: primary care physician workload assessment using EHR event log data and time-motion observations. Ann Fam Med. 2017;15(5):419-426.

5. Blendon RJ, Benson JM, Hero JO. Public trust in physicians-U.S. medicine in international perspective. N Engl J Med. 2014;371(17): 1570-1572.

6. Brega AG, Barnard J, Mabachi NM, et al. AHRQ Health Literacy Universal Precautions Toolkit. 2nd ed. Rockville, MD: Agency for Healthcare Research and Quality; 2015. AHRQ Publication No. 15-0023-EF.

7. Chou S-C, Venkatesh AK, Trueger NS, Pitts SR. Primary care office visits for acute care dropped sharply in 2002-2015, while ED visits increased modestly. Health Aff (Millwood). 2019;38(2):268-275.

8. Sinsky CA, Willard-Grace R, Schutzbank AM, Sinsky TA, Margolius $D$, Bodenheimer $T$. In search of joy in practice: a report of 23 high-functioning primary care practices. Ann Fam Med. 2013;11(3):272-278.

9. Anderson P, Halley MD. A new approach to making your doctornurse team more productive. Fam Pract Manag. 2008;15(7):35-40.

10. Hopkins $K$, Sinsky CA. Team-based care: saving time and improving efficiency. Fam Pract Manag. 2014;21(6):23-29.

11. Sinsky CA, Sinsky TA, Althaus D, Tranel J, Thiltgen M. Practice profile. 'Core teams': nurse-physician partnerships provide patientcentered care at an lowa practice. Health Aff (Millwood). 2010;29(5): 966-968.

12. Shaw JG. B.-J.C., Chan G, Mahoney M, Winget M. Physician burnout and joy of practice: early mixed methods findings from the implementation of Stanford primary care 2.0. Presented at: Academy Health Annual Research Meeting; June 25-27, 2017; New Orleans, Louisiana. Accessed Nov 27, 2018.
13. Funk KA, Davis $M$. Enhancing the role of the nurse in primary care: the RN "co-visit" model. J Gen Intern Med. 2015;30(12):1871-1873.

14. Lyon C, English AF, Chabot Smith P. A team-based care model that improves job satisfaction. Fam Pract Manag. 2018;25(2):6-11.

15. Jerzak J, Kerscher K. Restoring joy in practice through team based care. Presented at: Institute for Healthcare Improvement; December 2016; Orlando, Florida.

16. Meyer H. Bellin Health builds primary-care teams to boost physician, patient satisfaction. Mod Healthc. Nov 10, 2018.

17. Fiscella K, McDaniel SH. The complexity, diversity, and science of primary care teams. Am Psychol. 2018;73(4):451-467.

18. AMA STEPSforward. Implementing team-based care to increase practice efficiency. https://edhub.ama-assn.org/steps-forward. Published 2017. Accessed Mar 14, 2019

19. Huff C. Direct primary care: concierge care for the masses. Health Aff (Millwood). 2015;34(12):2016-2019.

20. Cassel CK. Can retail clinics transform health care? JAMA. 2018; 319(18):1855-1856.

21. Pollack S, Hochman M. Improvement happens: team-based primary care, an interview with Stuart Pollack. J Gen Intern Med. 2015;30(4): 521-528.

22. Tanio C, Chen C. Innovations at Miami practice show promise for treating high-risk Medicare patients. Health Aff (Millwood). 2013; 32(6):1078-1082.

23. Saba GW, Villela TJ, Chen E, Hammer H, Bodenheimer T. The myth of the lone physician: toward a collaborative alternative. Ann Fam Med. 2012;10(2):169-173.

24. Kellermann AL, Jones SS. What it will take to achieve the as-yetunfulfilled promises of health information technology. Health Aff (Millwood). 2013;32(1):63-68.

25. Dunn A, Whitmire B, Batch A, Fernando L, Rittmueller L. High spending growth rates for key diseases in 2000-14 were driven by technology and demographic factors. Health Aff (Millwood). 2018; 37(6):915-924.

26. Karsh B-T, Weinger MB, Abbott PA, Wears RL. Health information technology: fallacies and sober realities. J Am Med Inform Assoc. 2010;17(6):617-623.

27. Hoff T. Medical home implementation: a sensemaking taxonomy of hard and soft best practices. Milbank Q. 2013;91(4):771-810.

28. Safran DG. Defining the future of primary care: what can we learn from patients? Ann Intern Med. 2003;138(3):248-255.

29. Saultz JW, Lochner J. Interpersonal continuity of care and care outcomes: a critical review. Ann Fam Med. 2005;3(2):159-166.

30. Coiera E. When conversation is better than computation. J Am Med Inform Assoc. 2000;7(3):277-286.

31. Lee PR, Etheredge L. Clinical freedom: two lessons for the UK from US experience with privatisation of health care. Lancet. 1989; 1(8632):263-265.

32. Helfrich $C D$, Simonetti JA, Clinton $W L$, et al. The association of team-specific workload and staffing with odds of burnout among VA primary care team members. J Gen Intern Med. 2017;32(7): 760-766.

33. Schutte L. What you don't know can cost you: building a business case for recruitment and retention best practices. J Assoc Staff Physcian Recruit. Summer 2012. 